\title{
COVID-19: Feelings Experienced by Nurses, Physiotherapists, and Medical Doctors in a Brazilian Field Hospital
}

\author{
Joselito Adriano da Silva, Giulia Catissi, Leticia Bernardes de Oliveira, Daniela Reis Dal Fabbro, \\ Michele Jaures, Elisiane Plack, Gladys Cristina Borges, Fábio Racy, Andreia Ferreira Nunes, \\ Rose Mara Miranda, Denise Tiemi Noguchi Maki, Guilherme de Paula Pinto Schettino, \\ Claudia Regina Laselva, Eliseth Ribeiro Leão
}

Hospital Israelita Albert Einstein, São Paulo, Brazil

Email: Joselito.silva@einstein.br

How to cite this paper: da Silva, J.A., Catissi, G., de Oliveira, L.B., Dal Fabbro, D.R., Jaures, M., Plack, E., Borges, G.C., Racy, F., Nunes, A.F., Miranda, R.M., Maki, D.T.N., de Paula Pinto Schettino, G., Laselva, C.R. and Leão, E.R. (2021) COVID-19: Feelings Experienced by Nurses, Physiotherapists, and Medical Doctors in a Brazilian Field Hospital. Open Journal of Nursing, 11, 390-406.

https://doi.org/10.4236/ojn.2021.115034

Received: April 8, 2021

Accepted: May 28, 2021

Published: May 31, 2021

Copyright $\odot 2021$ by author(s) and Scientific Research Publishing Inc.

This work is licensed under the Creative Commons Attribution-NonCommercial International License (CC BY-NC 4.0). http://creativecommons.org/licenses/by-nc/4.0/ (c) (i) (8) Open Access

\begin{abstract}
Facing critical situations such as the ones triggered by COVID-19 may take healthcare professionals to confront their psychological resources, which may induce a higher stress level. We aimed to understand the feelings experienced by nurses, physiotherapists, and medical doctors in a field hospital dedicated to patients with COVID-19 in the biggest city of Brazil. Methods: We performed a qualitative study in a state field hospital in São Paulo city, Brazil, in a sample of 25 volunteer healthcare professionals. Participants answered to a sociodemographic electronic survey and were subjected to an individual semi-structured on-site interview. Results: Participants were mostly female (68\%), comprised eight nurses, eight physiotherapists, and nine medical doctors, had an average age of 36.8 years, and were professionally experienced. Speech analysis revealed two thematic categories (related to work and assistance in the pandemic) and 11 subcategories: adaptation to the scenario, stressing experience, psychological support, difficulties with workwear, safety with workwear, non-verbal communication, empathy, patient comfort, outstanding experiences, major challenges, and teamwork. Conclusion: Nurses, physiotherapists, and medical doctors' experiences while working in the field hospital were permeated by both positive and negative feelings. Those feelings originated directly from the fear of the unknown when dealing with a new disease without well-established scientific evidence, the use of medical workwear for long periods, and communication and environmental difficulties. In contrast, positive feelings, related to teamwork and empathy, arose and overlapped with the difficulties.
\end{abstract}




\section{Keywords}

Covid-19, Pandemic, Healthcare Professionals, Field Hospital

\section{Introduction}

Coronaviruses are zoonotic, RNA viruses from the Nidovirales order and Coronaviridae family that cause respiratory infections [1]. Up to date, known coronaviruses are the alphacoronaviruses HcoV-229E and HcoV-NL63, the beta coronaviruses $\mathrm{HCoV}-\mathrm{OC} 43$ and $\mathrm{HCoV}-\mathrm{HKU} 1$, SARS-CoV (the cause of Severe Acute Respiratory Syndrome, SARS), MERS-CoV (the cause of Middle East Respiratory Syndrome), and SARS-CoV-2. The latter is a new coronavirus described at the end of 2019 and causes COVID-19, classified as a pandemic by the World Health Organization [2].

Health authorities, through collective efforts, have been recommending containment measures, mainly preventive ones, since the answer to the COVID-19 pandemic is not linear and poses several still unanswered questions to the scientific community. Up to now, one main and efficient strategy for containment has thus been social distancing [3].

Aiming to reduce the pandemic impact, i.e. to decrease infections and death numbers, some countries have adopted the following measures: isolation of suspected cases, large-scale testing, travel restriction, gathering avoidance, the closing of schools and universities, social distancing of the elderly and other risk groups, and quarantine on the general population [4]. It is estimated that these measures lead to the "flattening the curve" of disease, favoring a smaller incidence in a certain period and reducing chances of lacking hospital beds, ventilators, and other supplies due to a sudden increase in demand, which is associated with higher mortality [5].

However, these measures may not suffice for the population to receive specialized and timely medical care, due to the limitation of beds, inputs, or human resources. Thus, as part of the action to fight SARS-CoV-2, authorities of the municipality of São Paulo, Brazil created the Field Municipal Hospital of Pacaembu (HM Camp, Hospital Municipal de Campanha do Pacaembu, in the original). The Hospital Israelita Albert Einstein, São Paulo temporarily managed and operated this healthcare service [6].

A field hospital is a unit that has the necessary structure to provide health care to the population. Currently, these units are relevant protagonists due to emergencies that include the lack of beds in times of catastrophes and epidemics [7].

The literature has been reporting the usual development of negative feelings such as fear, anguish, concern, anger, feeling of helplessness, anxiety, among others, in the current pandemic context. Such feelings are generated by the uncertainty of what is to come and by the imposed social isolation, which leads people, in a risky situation, to experience the conflict of being away from daily 
functions, although often family, finance, and social conditions do not allow them this option [8].

Besides, coping with critical situations such as those generated by COVID-19 may lead healthcare professionals to be confronted with their psychological resources, possibly generating higher stress levels [9]. Also, many professionals may feel unprepared to perform clinical interventions in patients infected with a new virus, for which knowledge is limited and well-established protocols or clinical treatments are lacking [10].

These problems may be exacerbated in a field hospital, since healthcare professionals suddenly move to a unit that is unfamiliar, with a structure and work processes that differ from those of their units of origin, to provide care in the face of a little-known disease [11].

Thus, this study originated from the need to understand the factors that may impact the life of healthcare professionals who provide care to patients with suspected or confirmed COVID-19 diagnosis, in a field hospital.

Several studies have explored this theme in the universe of hospital healthcare, in areas that include intensive therapy of adults [12] or infants [13] and oncology [14]. However, we are not aware of reports on the problematics of field hospitals, which, in the current reality, present peculiar situations that demand capacity of adaptation to a new workplace and makeshifts, which may generate feelings of anxiety, stress, and suffering.

When the field hospital was structured, health professionals did not have established protocols for Covid-19, in addition, news about the spread of the virus in other countries triggered a lot of fear and insecurity in the professionals who needed to care for these patients. Therefore, it was extremely relevant to carry out this study to understand the feelings experienced during the work of nurses, doctors and physiotherapists who worked at the field hospital.

Therefore, this study aimed to understand the feelings experienced by nurses, physiotherapists, and medical doctors in a field hospital dedicated to patients with COVID-19 in the biggest city in Brazil.

\section{Methods}

We performed a cross-sectional, prospective, field study with a qualitative approach, in a field state hospital managed by a large private hospital in the municipality of São Paulo, Brazil.

HM Camp was built to harbor 184 beds in nursery and 16 in a stabilization room; it is supervised by the Municipal Health Secretary of São Paulo. Established as a closed-door unit, it has exclusively received low and medium complexity patients, transferred by ambulance from health facilities in the city (hospitals and emergency units).

The HM Camp structure was built in 12 days in a total area of $6300 \mathrm{~m}^{2}$ and harbored 10 nurseries and 200 beds. During the operation period, 588 healthcare professionals cared for the hospitalized patients, and 1515 patients were received, 
and three deaths recorded. Of all cases treated, 54\% were men, and 51\% were elderly [15]. The hospital closed its activities on June 29, 2020.

\subsection{Sample}

We recruited nurses, physiotherapist, and medical doctors who worked at the field hospital on different shifts and those who met the following inclusion criteria: both sexes and working in the stabilization room. The data saturation criterion was used for suspension of conducting new interviews [16]. Therefore, the interviews were carried out until the moment when there was convergence/repetition of the statements, in relation to the phenomenon studied, which occurred with 25 professionals who participated in the study on a voluntary basis.

\subsection{Sample Characterization}

Participants completed a sociodemographic questionnaire for sample characterization, composed of the following variables: sex, age, education, position held, marital status, family income, time since graduation, whether at the first job, whether working in another service, whether having worked in the hospital area before the pandemic, number of current working weeks in the field hospital, and the time and type of employment contract.

\subsection{Semi-Structured Interview}

The semi-structured interview had the guiding question: "How do you feel working in a field hospital dedicated to the treatment of patients with suspected and confirmed COVID-19?" Other open questions were related to resilience and aimed to contextualize the participant's reality in the new COVID-19 pandemic. To better understand these feelings, we asked the participants to talk about: how he/she was recruited to work in the field hospital, how was the feeling when entering the tent for the first time, adaptation in new infrastructure, difficulties with contact insulation clothes, how he/she felt in relation to the recognition or not of facial expressions among professional attorneys, what were the biggest challenges, how he/she dealt with these daily feelings.

The response time was unlimited so that the participants could fully describe their experiences.

\subsection{Operationalization of Data Collection}

Participants were invited via e-mail by the study principal investigator, who worked in the HM Camp. In the e-mail, participants were informed of the research objectives. After electronically agreeing to the FICF, they had access to the sociodemographic questionnaire, via the Google Forms platform.

The interview was scheduled according to the participant's availability, to avoid interfering with work or personal activities. Interviews were conducted and recorded by the principal investigator, at the HM Camp facilities, in a private, calm, and quiet room from June 6 to July 3, 2020. 
Data collection ended when qualitative data on the feelings reported began to be recurrent in the interviewer's analysis.

\subsection{Data Analysis}

Sociodemographic and clinical data were analyzed quantitatively and presented descriptively in graphs and tables.

A complete transcription of the recording of the participants' speeches was performed and submitted to Bardin's content analysis [17] according to the following phases: 1) organization of the analysis; 2) coding; 3) categorization; 4) result treatment, inference, and interpretation.

To maintain participants' anonymity, a numbered coding was used for each interview, by category: "N" for nurses, "P" for physiotherapists, and "MD" for medical doctors. This avoided any type of connection between the content of the interviews and the participants' identity in the transcripts presented in the results section.

\section{Results}

\subsection{Sociodemographic Characteristics of Nurses, Physiotherapists, and Medical Doctors}

The sample of the study was composed of 25 professionals. About the profile of the participants, the majority were female (68\%), an average age of 36.8 years, with postgraduate degrees (36\%), the most prevalent professional category were medical doctors (36\%), married (60\%), family income above five salaries (60\%). About period of academic education, $56 \%$ of the participants graduated more than 10 years ago. Most of the participants worked in more than one hospital $(84 \%)$, and $92 \%$ already worked in a hospital area before the pandemic. About risk factors for Covid-19, only one participant (4\%) reported asthma. Regarding family members, the most prevalent risk factors for Covid-19 were hypertension (37\%) and diabetes (19\%) (Table 1).

Table 1. Sociodemographic characteristics of nurses, physiotherapists, and medical doctors.

\begin{tabular}{|c|c|c|}
\hline \multicolumn{3}{|c|}{ SOCIODEMOGRAPHIC DATA } \\
\hline VARIABLE & $\mathrm{n}=25$ & $\%$ \\
\hline \multicolumn{3}{|c|}{ SEX } \\
\hline Female & 17 & $68 \%$ \\
\hline Male & 08 & $32 \%$ \\
\hline \multicolumn{3}{|c|}{ AGE } \\
\hline Average & \multicolumn{2}{|c|}{36.8} \\
\hline Minimum & \multicolumn{2}{|c|}{25} \\
\hline Maximum & \multicolumn{2}{|c|}{49} \\
\hline $\mathrm{SCH}$ & & \\
\hline
\end{tabular}




\section{Continued}

$\begin{array}{ccc}\text { Postgraduate } & 18 & 72 \% \\ \text { Graduate } & 03 & 12 \% \\ \text { Master } & 03 & 12 \% \\ \text { Doctorate } & 01 & 4 \%\end{array}$

PROFESSION

Medical doctor

$09 \quad 36 \%$

Nurse

$08 \quad 32 \%$

Physiotherapist

$08 \quad 32 \%$

MARITAL STATUS

Married

Single

$08 \quad 32 \%$

Divorced

02

$8 \%$

FAMILY INCOME

More than 5 minimum wages

Between 4 and 5 minimum wages

Rather not answer

Between 1 and 3 minimum wages

$15 \quad 60 \%$

$07 \quad 28 \%$

$02 \quad 8 \%$

$01 \quad 4 \%$

PERIOD OF ACADEMIC EDUCATION

More than 10 years

Between 6 and 10 years

Between 2 and 5 years

Less than a year
$14 \quad 56 \%$

$06 \quad 24 \%$

$04 \quad 16 \%$

$01 \quad 4 \%$

FIRST JOB?

$\begin{array}{lcc}\text { No } & 23 & 92 \% \\ \text { Yes } & 02 & 8 \% \\ \text { WORK IN OTHER PLACES } & & \\ \text { Yes } & 21 & 84 \% \\ \text { No } & 04 & 16 \%\end{array}$

ACT IN THE HOSPITAL AREA BEFORE THE PANDEMIC

$\begin{array}{lcc}\text { Yes } & 23 & 92 \% \\ \text { No } & 02 & 8 \%\end{array}$

TESTED POSITIVE FOR COVID-19

$\begin{array}{lll}\text { No } & 18 & 72 \% \\ \text { Yes } & 07 & 24 \%\end{array}$

HEALTH PROFESSIONAL COVID-19 RISK FACTOR

$\begin{array}{ccc}\text { None } & 24 & 96 \% \\ \text { Asthma } & 01 & 4 \%\end{array}$

FAMILY COVID-19 RISK FACTOR* 


\begin{tabular}{ccc}
\hline Hypertension & 16 & $37 \%$ \\
Diabetes & 08 & $19 \%$ \\
Cancer & 02 & $5 \%$ \\
Asthma & 01 & $2 \%$ \\
Obesity & 01 & $2 \%$ \\
Chronic obstructive pulmonary disease & 01 & $2 \%$ \\
Not specified & 07 & $16 \%$ \\
Not applicable & 07 & $16 \%$ \\
\hline
\end{tabular}

Note: $\mathrm{n}=$ sample size; ${ }^{\star} \mathrm{n}=43$ because it is about the relatives of the participants.

Our analysis of the reported experiences of working in the field hospital revealed two thematic categories and 11 subcategories emerged, as described below.

\subsubsection{Work-Related Aspects}

\section{1) Time for adaptation to the scenario}

Participants reported their view of the pandemic scenario and their adaptation to the new work situation:

"But as time went by, everything improved, vacancies started to appear more quickly, everything improved and enhanced every day." N1

"When we think of a field hospital [...] You imagine everything more or less like this, improvised stuff, people sitting on the floor, those very dramatic things that we see in Doctors Without Borders. [...] Then when I saw the tent, I saw that it had a structure, that it was a real hospital. [...] With all the hospital resources." MD1

"It looked like a movie, an unbelievable thing, you are inside a football stadium but it is a hospital structure." P3

\section{2) A stressful experience}

Stressful situations were observed in the daily life of the field hospital, especially concerning working conditions in a hospital built inside a football stadium:

"Sometimes I didn't go to the toilet so I wouldn't have to take my clothes off, so there was also a feeling of I don't want to waste the PPE [personal protective equipment] so it will not run out." N8

"The feeling that I was participating in a movie [...] Entering a concentration camp, you see that stadium. [...] that tall tent, with that light, that white light. [...] The feeling was that I was entering a World War II movie." MD5

"In the beginning they could not use a cell phone, right, they could not enter [to work] with a cell phone, they could not have any contact with the outside world. [...] You couldn't take a mask off, to smile, when they didn't recognize you. They were in that white place, that they were cold, they were hot, so their suffering reflected a little on the team too." P2 


\section{3) Psychological support}

Regarding the need for psychological support to help to cope with the pandemic in the field hospital, we perceived ambiguous feelings:

"I had the opportunity to talk to a psychiatrist, he could hear me, I could talk a little." N7

"I was sad when I saw the patient talking to the family member, telling that they were tired, that they were going to be intubated, I cried a little, but that was on the spur of the moment and I didn't look for help." MD8

"The field hospital had a program called OUVID, which we could get in touch with professionals, psychologists who were always willing to listen to us and help us on that journey." P5

\section{4) Difficulties with workwear}

Feelings about the act of dressing up emerged:

"I wear glasses, so even though I adapted the mask, a little air escaped, fogged up, I couldn't see well, it hurt a lot behind my ear [...] Probably by overlapping my glasses [...] And in the beginning I had shortness of breath." N8

"(Because of the mask) Many times you could not understand what people said, it's a little uncomfortable because I worked with many people, I met many people and I have no idea what they look like." MD3

"P $m$ inside the tent and I need to drink some water, either I get totally undressed and go out or $1 m$ thirsty, we don't have that option to enter somewhere where I can take a sip of water or even go to the toilet." P6

\section{5) Security with the workwear provided}

Regarding workwear, some participants addressed aspects related with the safety of the protective equipment provided by the institution:

"There was no lack of material, we were well equipped with both a mask and an apron, the clothes provided had protection for feet and head." N2

"I think that if we felt uncomfortable in the beginning, then we felt protected. [...] I think this care was a very important thing. [...] We felt that we could leave and return that we would have the same material again. [...] I think its everyone's fear because in some countries people didn't even went out to the toilet because they wouldn't have PPE." MD7

"One hundred percent safe, much safer inside the tent than anywhere else ... at the market, at the pharmacy, in the traffic from home to here." P1

\subsubsection{Aspects Related with Assistance in the Pandemic}

\section{1) Non-verbal communication}

When talking about the lack of facial expression recognition due to the use of the workwear, unusual situations emerged, from which we highlight:

"It was important because we were recognized people by the look in their eyes. [...] I think our eyes say much more than the smile." $\mathrm{N} 1$

"I think I tend to look people in the eyes when $I m$ talking and I think that may have helped at some point. [...] I work in the operating room, I see people wearing masks and clothes and glasses all the time." MD7 
"You didn't know much what the other person was thinking just by looking in their eyes. [...] We need a lot more than looking in the eyes, in general. [...] You didn't know if the person was angry, was anxious, was happy, or if she had understood what you had told her." P2

\section{2) Empathy}

When we explored whether, during the participants' professional experience, they had already felt something similar to what they experienced in the field hospital, it was possible to identify situations that highlight the feeling of empathy of these professionals:

"I kept putting myself in the patient's shoes. [...] Many of them did not have a cell phone to talk to family members, it was only by video call, so it impacted me a lot because they only talked to us, right, we were kind of a substitute for their family." N6

"One thing is you meeting the patient and the family member day by day in the bedroom. [...] Another is the family member not talking to the patient. [...] When you spoke, you were the link between patient and family, I think it is something that we do not experience on a daily basis and I think that we will not experience it again." MD6

"It was very cold at night, but I think it was because it was all too white because there was no wall, there is nothing to distract, we asked if they had slept well at night they say it was more or less because of the mattress." P2

\section{3) Patient comfort}

Because it was structured in a football stadium, the field hospital presented challenging situations due to facility-related conditions. Thus, when we sought to know about temperature, lighting, and noise, the concern of professionals in providing a cozy environment for patients was evident:

"I was very worried about them and had to go back all the time to see if they were comfortable and they were feeling very cold." N5

"I thought it was beautiful how the nursing team, mainly, as well as the leadership itself, became involved in providing for patients. [...] They went after eye patches, people went after a blanket, how many patients I didn't see with a blanket underneath, others on top, because it heats up much more, the thermal blankets." MD9

\section{4) Outstanding Experiences}

During the interviews, several situations emerged, which resulted in reports of remarkable experiences:

"She had a bad history with her children, you know, so it caught a lot my attention, she didn't have the opportunity to reconcile with her children, unfortunately [...]. Then you see that she was already a white-haired lady, she for all her life she had a lifetime to do this, or her children, and they didn't succeed, so this is really sad." $\mathrm{N} 1$

"I remember a case of a patient who had COPD and he met the criteria for intubation. [...] They called his family and so it was, it was the entire family, 
about four children and everyone saying they loved him, he couldn't barely talk due to the shortness of breath he was having and that goodbye was very touching. [...] This patient was transferred, I think that after two, three days he died in another hospital. So it was very touching for me, because that time it was a real farewell." N6

"There were several times that they came underdressed, it was damn cold, had their clothes open and were entering the field hospital, sometimes coming from a place where they were not properly welcomed." MD2

"Making the video call from patient to family, and the family and patient said goodbye, like many times the patient did not say see you soon, said goodbye, I think that was the saddest." P6

\section{5) Major Challenges}

Challenges were numerous and of different natures:

"Spending sleepless nights again, which I hadn't done for more than three years. So that was a physical challenge. Yes, there was another challenge, which was caring of patients in a specialty that is not mine." MD9

"Now that I did medical clinic, it got a little more comfortable to do it again if needed in a new pandemic." MD3

"The fact that it does not have a normal hospital structure. [...] Sometimes I needed to do some procedures that a field hospital was not designed for. [...] We had patients in very serious conditions and I think that was the main challenge of the day-to-day in the hospital." P5

"I think the challenge of trying to lead in a certain technical way a group of people so heterogeneous." $\mathrm{P} 7$

6) Teamwork

Regarding the feelings on the work performed in the field hospital, the importance of teamwork was evident in the highlighted statements:

"It was something that we managed to give to the population,

I say Brazilian population because São Paulo is a mini Brazil. [...] We were able to give the Brazilian population the best medical support they could have in a public service. [...] That, of the professionals commitment. [...] They always wanted to help people, they were always very dedicated and we don't see that anywhere." MD5

"Because if it weren't for everyone helping each other, it wouldn't have been a good and rewarding experience the way it was. [....] Everyone wanted to be there." MD6

\section{Discussion}

In this study, which sought to understand the feelings experienced by nurses, physiotherapists, and medical doctors at a field hospital dedicated to confirmed or suspected patients with COVID-19, we found that the multi-professional team experienced feelings strongly linked to the adaptation to the field hospital. In the testimonies, the difficulty of keeping the personal protective equipment 
(PPE) for long periods was evident, identically to what was reported by other studies related to the pandemic [18] [19]. The three professional categories reported high difficulty with the goggles overlapping, pain behind the ear, feeling of suffocation with the mask, and difficulty in removing the workwear for breaks or drinking of water during shifts. Similar issues were reported by professionals who worked at Hubei Hospital in China, who, in addition to the discomfort, reported skin lesions due to prolonged use of PPE [18] [19]. This was not an issue in the HM Camp because of the use of a nasal protector and the encouragement to take breaks during shifts, to minimize risks of skin lesions and suffocation.

Being built in a football field, therefore in a large open area, HM Camp presented particularities that greatly differed from hospital buildings. Temperature fluctuations and lighting conditions inside the tent proved to be highly challenging for professionals. The field hospital operated from March to June 2020, a period with highly cold nights in São Paulo. As a result, participants reported high levels of discomfort felt by patients and professionals, especially during night shifts. The field hospital was structured to reduce the occupancy of the public network hospitals of São Paulo and receive low complexity patients who needed continuity of treatment. Thus, it was common to admit patients who arrived at the tent all the time. One participant reported suffering from receiving patients feeling very cold and with inadequate clothing. The literature emphasizes that welcoming contributes to quality and humanized care and facilitates comprehensive care promotion so that professionals have a holistic view of the human being to be cared for [20]. Providing comfort in nursing practice is an essential objective, to be achieved through assistance, and aims, therefore, to meet the expectations and needs of each patient, in this way achieving more humane and individualized care [21] [22] [23].

These aspects were continuously challenging to the nursing team, which managed to mitigate them through several assisting measures, from which we highlight the use of thermal blankets, caps, scarfs, and socks.

One of the experienced sensations was related to difficulties in communicating due to the personal protective equipment. This issue was also observed in Iran, where nurses reported severe discomfort due to PPE use in addition to an impaired understanding of body language [24].

The limited communication of isolated patients, especially with family members, was a topic that went beyond the walls of the hospitals and was widely debated in social media and explored by the media in general. It was a very critical and distressing situation that needed to be managed. Around the world, health professionals sought to minimize patient and family loneliness by facilitating remote communication devices [25]. Given that many patients are elderly or disabled, with difficulties in using digital technologies on their own, nurses and doctors have implemented the use of video calls [26]. In this sense, the professionals who worked in the field hospital showed high empathy to address this need. Considering that, in many cases, there was the uncertainty that clinical evolution would be positive, the assistance team made video calls to family 
members before performing the intubation procedure. Patients could talk to their loved ones and, in some cases, there was the possibility of a moment of saying goodbye. These reports reinforce the need, already noted in the literature, for skills on reporting difficult news and maintaining good communication in tense moments by the professionals who work directly in the care of critically ill patients [26]. This is essential for greater adherence during care, especially in a critical situation such as the pandemic has become. Communication difficulties in everyday situations of patient care are already notorious [27], and it has been one of the greatest challenges in the pandemic, especially in the most critical cases.

Some participants experienced new situations, sometimes needing flexibility and resilience to face this and other challenges that arose during the pandemic. Pediatricians, for example, reported certain insecurity in attending adult patients at the field hospital. A similar situation was observed in two large hospitals in the United States [28] [29], which reduced the admission of pediatric patients, temporarily relocating doctors and nurses to intensive care units for adult patients.

The scenario contributed to feelings of anxiety and suffering being reported by professionals during the care of critically ill patients in the stabilization room, as they were the ones being wit patients at these moments and without the presence of the family. In agreement, other studies revealed high levels of psychological distress among nurses during care in the pandemic of COVID-19 [30] [31] [32]. Fear was a prominent feeling in this study as well as in the literature. Fear of infection and death or about infecting family and friends can potentiate dysphoric mental states [33].

This is highly relevant, since fear being an experience that usually paralyzes people, it is possible to imagine the degree of additional energy that health professionals had to expend, in a situation that paralyzing/stopping was not possible. However, professionals indicated that the institution offered a program to help them face the impact of the COVID-19 pandemic on the mental health of the institution's employees since the first weeks of March. The professionals highlighted the therapists' availability (psychologist and/or psychiatrist) and the moments of decompression with self-care practices focused on relaxation carried out in groups in the areas in which the employees work and conducted by physical education professionals and an integrative therapist. More than 110 hours were dedicated to the employees' mental health, with actions carried out inside the tent, during working hours, in a rotation scheme. As also observed in our study, the need for support for nursing collaborators and other health professionals was a recurring theme across the country to reduce the negative experience in confronting the coronavirus. Like our institutional initiative, the Federal Nursing Council stipulated the National Commission on Mental Health Nursing to support nursing professionals. A Mental Health Nursing Care project was created for nursing professionals who work on the front line of the pan- 
demic [26]. In the same study, it was revealed that the main feelings described by the health professionals assisted by the project were related to anxiety due to the lack of PPE, pressure from managers and news; stress due to increased attendance and high mortality; fear of the risk of being contaminated and contaminating the family; ambivalence, being recognized by the population are also discriminated against and avoided; depression generated by loneliness, death of colleagues and emotional exhaustion or exhaustion [26].

Although the literature has broadly pointed out the need for psychological support to health professionals during the pandemic [19] [24], this was not a reality for many institutions in other countries. In a study carried out with nine nurses and four medical doctors who worked in five different hospitals in China, a strong psychological distress on these professionals was evident, and there is no mention that they could rely on a support network [34].

Notable experiences during the working period in the field hospital also emerged from the professionals' accounts. One of the participants mentioned the case of a patient who had a relationship problem with his/her family. The participant's attention was drawn to the fact that, in a very delicate moment, there was no possibility for reconciliation. Family relationships allow the person to receive emotional and psychological support, human and ethical values, in addition to other tools necessary for full physical and mental balance [35], which unfortunately in this case did not occur. This situation reinforced reflections on the finitude and brevity of human life, both for patients and health professionals.

It was also highlighted, in the testimonies, that the success of the field hospital was achieved through teamwork, permeated by the mutual respect between the different categories that harmoniously developed their roles in the areas of their responsibility, through synergy knowledge, experience, and skills. Working as a team has been identified as fundamental in the dynamics of interrelationships and in the link between the components, enhancing the work performance and leading to higher quality care for patients [36]. More and more institutions, and in particular health institutions, have been looking for professionals with a profile compatible with teamwork. Currently, the most coveted professionals are those with specific skills and diverse clinical interests, which the pandemic situation has revealed as fundamental aspects for future scenarios [37]. Collaboration, whether social, scientific, or even citizen, amid so much suffering, is already one of the main legacies of this pandemic.

It should be noted that participants were from the same region and thus our findings may not be suitable for extending to other hospital settings or regions, as cultural and social aspects vary between regions and countries. However, it is a relevant report on the experience of healthcare professionals during the short period of operation of the hospital during COVID-19 confrontation, as well as on the singularities arising from assistance with protocols that are still poorly defined and from which healthcare professionals obtained little information.

Therefore, this research contributes to facilitating the work of other mul- 
ti-professional teams in the context of a pandemic, considering that the HM Camp hospital was the first to be built for the care of patients with SARS-COV-2 in Brazil. Reflecting on the experience of these professionals can help managers and health teams in situations where they are called to work in a field hospital, in other emergencies around the world.

\section{Final Considerations}

Nurses, physiotherapists, and medical doctors experienced different feelings during the period of operation in the field hospital. These feelings directly originated from the fear of the unknown when dealing with a new disease with no protocols with well-established scientific evidence, the use of workwear for prolonged periods, and communication and environmental difficulties. On the other hand, positive feelings overlapped with the difficulties, from which we highlight the empathy to help people in a time of pandemic and overcrowding in healthcare services. In addition, besides the teamwork, also important was the collaboration provided by everyone and their willingness, allowing a better understanding of how to act in face of a new virus that always demanded, and continues to demand, new learnings.

\section{Declarations}

\section{Ethics Approval and Consent to Participate}

The study was submitted to the National Research Ethics Commission, according to the flowchart of ethical processing of research protocols related to COVID-19 (Ministry of Health, 2020), and approved on August 25, 2020, under the CAAE: 33653020.3.0000.0071.

The research followed the ethical and legal precepts of Resolution 466/2012 from National Health Council.

\section{Consent for Publication}

All participants signed the free and informed consent form (FICF).

\section{Availability of Data}

The data are available on request from corresponding author.

\section{Funding}

This research did not receive any specific grant from funding agencies in the public, commercial or not-for-profit sectors.

\section{Conflicts of Interest}

The authors declare no competing interests.

\section{References}

[1] Brazil. Ministry of Health (2020) Clinical Management Protocol for the New-Co- 
ronavirus (2019-nCoV). Ministry of Health, Brasília (DF).

https://portalarquivos2.saude.gov.br/images/pdf/2020/fevereiro/11/protocolo-mane jo-coronavirus.pdf

[2] Brazil. Ministry of Health (2020) Coronavirus: What You Need to Know and How to Prevent Contagion. Ministry of Health, Brasília (DF). https://coronavirus.saude.gov.br/

[3] Brazil. Ministry of Health (2020) Health Surveillance Secretariat. Special epidemiological bulletin COE-COVID-19. Ministry of Health, Brasília (DF).

https://portalarquivos.saude.gov.br/images/pdf/2020/April/27/2020-04-27-18-05h-B EE14-Boletim-do-COE.pdf

[4] Silva, M.C. and Machado, M.H. (2020) Health and Work System: Challenges for the Nursing in Brazil. Ciência \& Saúde Coletiva, 25, 7-13.

[5] Brooks, S.K., Webster, R.K., Smith, L.E., Woodland, L., Wessely, S., Greenberg, N., et al. (2020) The Psychological Impact of Quarantine and How to Reduce It: Rapid Review of the Evidence. The Lancet, 395, 912-920.

https://doi.org/10.1016/S0140-6736(20)30460-8

[6] Municipal Health Secretariat (São Paulo) (2017) Health Surveillance Coordination. Coronavirus: Hospitals. Municipal Health Secretariat, São Paulo.

https://www.prefeitura.sp.gov.br/cidade/secretarias/saude/vigilancia_em_saude/doe ncas_e_agravos/coronavirus/index.php?p=296086

[7] Brazil. Ministry of Health (2020) Health Regulates Isolation and Quarantine Conditions. Ministry of Health, Brasília (DF).

https://repositorio.ucb.br:9443/jspui/bitstream/123456789/8241/3/LaraMonalisaAlv esdosSantosArtigo2017.pdf

[8] United Nations (2020) COVID-19 Highlights Nurses' Vulnerability as Backbone to Health Services Worldwide. United Nations, New York.

https://news.un.org/en/story/2020/04/1061232

[9] Huang, J.Z., Han, M.F., Luo, T.D., Ren, A.K. and Zhou, X.P. (2020) [Mental Health Survey of Medical Staff in a Tertiary Infectious Disease Hospital for COVID-19]. Zhonghua Lao Dong Wei Sheng Zhi Ye Bing Za Zhi, 38, 192-195. (In Chinese)

[10] Malta, M., Rimoin, A.W. and Strathdee, S.A. (2020) The Coronavirus 2019-nCoV Epidemic: Is Hindsight 20/20? EClinicalMedicine, 20, 100289.

https://doi.org/10.1016/j.eclinm.2020.100289

[11] Miranda-Sá Jr., L.S. (2013) An Introduction to Medicine. Federal Council of Medicine, Brasília, Volume 1: The Doctor.

https://portal.cfm.org.br/images/stories/biblioteca/introduo\%20e\%20medicina_livr o.pdf

[12] Martins, J.T., Robazzi, M.L. and Garanhani, M.L. (2009) Feelings of among Intensive Care Unit Nurses. Cienc Enferm, 15, 45-53.

[13] Rocha, D.D., Nascimento, E.C., Raimundo, L.P., Damasceno, A.M. and Bondim, H.F. (2017) Feelings Experienced by Nursing Professionals in the Face of Death in Neonatal. Mental, 11, 546-560.

[14] Avellar, L.Z., Iglesias, A. and Valverde, P.F. (2007) Psychological Suffering of Nursing Professionals at an Oncology Unit. Psicologia em Estudo, 12, 475-481. https://doi.org/10.1590/S1413-73722007000300004

[15] Mansuido, M. (2020) Coronavirus: Closure of the Pacaembu Field Hospital. São Paulo City Council, São Paulo.

http://www.saopaulo.sp.leg.br/coronavirus/blog/coronavirus-fechamento-do-hospit al-de-campanha-do-pacaembu/ 
[16] Gomes, R. (2007) Analysis and Interpretation of Qualitative Research Data In: Minayo, M.C.S., Organizer, Social Research: Theory, Method and Creativity, 25th Edition, Vozes, Petrópolis, 79-107.

[17] Bardin, L. (2004) Análise de conteúdo. Edições, Lisboa, 70.

[18] British Society for Cutaneous Allergy \& British Association of Dermatologists COVID-19-Occupational Skin Disease. Update on Occupational Skin Disease during the Coronavirus Pandemic. British Association of Dermatologists, London. https://www.bad.org.uk/shared/get-file.ashx?itemtype=document\&id=6675

[19] Galehdar, N., Kamran, A., Toulabi, T. and Heydari, H. (2020) Exploring Nurses' Experiences of Psychological Distress during Care of Patients with COVID-19: A Qualitative Study. BMC Psychiatry, 20, Article No. 489. https://doi.org/10.1186/s12888-020-02898-1

[20] Guedes, M.V., Henriques, A.C. and Lima, M.M. (2013) Embracement in an Emergency Service: Users' Perception. Revista Brasileira de Enfermagem, 66, 31-37. https://doi.org/10.1590/S0034-71672013000100005

[21] Pott, F.S., Stahlhoefer, T., Felix, J.V. and Meier, M.J. (2013) Comfort and Communication Measures in Nursing Caring Actions for Critically Ill Patients. Revista Brasileira de Enfermagem, 66, 174-179. https://doi.org/10.1590/S0034-71672013000200004

[22] Tomey, A.M. and Alligood, M.R. (2004) Nursing Theorists and Their Work: Models and Theories of Nursing. 5th Edition, Lusociência, Loures.

[23] Kolcaba, K.Y. (1994) A Theory of Holistic Comfort for Nursing. Journal of Advanced Nursing, 19, 1178-1184. https://doi.org/10.1111/j.1365-2648.1994.tb01202.x

[24] Du, J., Dong, L., Wang, T., Yuan, C., Fu, R., Zhang, L., et al. (2020) Psychological Symptoms among Frontline Healthcare Workers during COVID-19 Outbreak in Wuhan. General Hospital Psychiatry, 67, 144-145.

https://doi.org/10.1016/j.genhosppsych.2020.03.011

[25] Webster, P. (2020) Virtual Health Care in the Era of COVID-19. The Lancet, 395, 1180-1181. https://doi.org/10.1016/S0140-6736(20)30818-7

[26] de Humerez, D.C., Ohl, R.I.B. and da Silva, M.C.N. (2020) Mental Health of Brazilian Nursing Professionals in the Context of the COVID-19 Pandemic: Action of the Nursing Federal Council. Cogitare Enfermagem, 25, e74115. https://revistas.ufpr.br/cogitare/article/view/74115/pdf_en https://doi.org/10.5380/ce.v25i0.74115

[27] Back, A., Tulsky, J.A. and Arnold, R.M. (2020) Communication Skills in the Age of COVID-19. Annals of Internal Medicine, 172, 759-760. https://doi.org/10.7326/M20-1376

[28] Sternberg, S. (2021) Coronavirus Is Causing a Reshuffling of Pediatric Care. U.S. News, Washington DC.

https://www.usnews.com/news/health-news/articles/2020-04-10/coronavirus-is-cau sing-a-reshuffling-of-pediatric-care

[29] Hatfield, M. (2020) How Pediatric Providers Care for Adult Patients during Pandemic. Children's Hospital Association, Washington DC.

https://www.childrenshospitals.org/Newsroom/Childrens-Hospitals-Today/Articles /2020/05/How-Pediatric-Providers-Care-for-Adult-Patients-During-Pandemic

[30] Allsopp, K., Brewin, C.R., Barrett, A., Williams, R., Hind, D., Chitsabesan, P., et al. (2019) Responding to Mental Health Needs after Terror Attacks. BMJ, 366, 14828. https://doi.org/10.1136/bmj.14828 
[31] Amin, S. (2020) The Psychology of Coronavirus Fear: Are Healthcare Professionals Suffering from Corona-Phobia? International Journal of Healthcare Management, 13, 249-256. https://doi.org/10.1080/20479700.2020.1765119

[32] Gonzales, R.M. (1999) A Auto-Percepção-A Journey Experienced by Nurses. In: Gonzales, R.M., Beck, C.L. and Denardin, M.L., Eds., Care Scenarios: Application of Nursing Theories, Pallotti, Santa Maria, 15-60.

[33] Hui, D.S., Azhar, E.I., Kim, Y.J., Memish, Z.A., Oh, M.D. and Zumla, A. (2018) Síndrome respiratória do Oriente Médio coronavírus: Fatores de risco e determinantes da transmissão primária, domiciliar e nosocomial. The Lancet Infectious Diseases, 18, e217-e227.

https://www.who.int/emergencies/diseases/novel-coronavirus-2019 https://doi.org/10.1016/S1473-3099(18)30127-0

[34] Liu, Q., Luo, D., Haase, J.E., Guo, Q., Wang, X.Q., Liu, S., et al. (2020) The Experiences of Health-Care Providers during the COVID-19 Crisis in China: A Qualitative Study. The Lancet Global Health, 8, e790-e798. https://doi.org/10.1016/S2214-109X(20)30204-7

[35] Oliveira, M.M. and Jorge, M.S. (1998) Mentally Ill and His Relationship with the Family. In: Proceedings of the V Meeting of Researchers in Mental Health and VI Meeting of Specialists in Psychiatric Nursing, Ribeirão Preto, SP, 379-388.

[36] Shimizu, H.E. and Ciampone, M.H. (2004) The Representations of Nursing Auxiliaries and Technicians about Team Work at an Intensive-Care Unit. Revista Latino-Americana de Enfermagem, 12, 623-627.

[37] Jassar, A.S., Perkins, K.E. and Sundt, T.M. (2021) Teamwork in the Time of Coronavirus: An MGH Experience. Journal of Cardiac Surgery, 36, 1644-1648. https://doi.org/10.1111/jocs.15036

\section{Abbreviations and Acronyms}

CONEP, National Research Ethics Commission (from the original Comissão Nacional de Ética em Pesquisa)

FICF, Free Informed Consent Form

HM Camp, Field Municipal Hospital of Pacaembu (from the original Hospital Municipal de Campanha do Pacaembu)

PPE, Personal Protective Equipment

PMSP, Municipality of São Paulo (from the original Prefeitura Municipal de São Paulo)

SARS, Severe Acute Respiratory Syndrome 